Thomas C.G. Bosch · David J. Miller
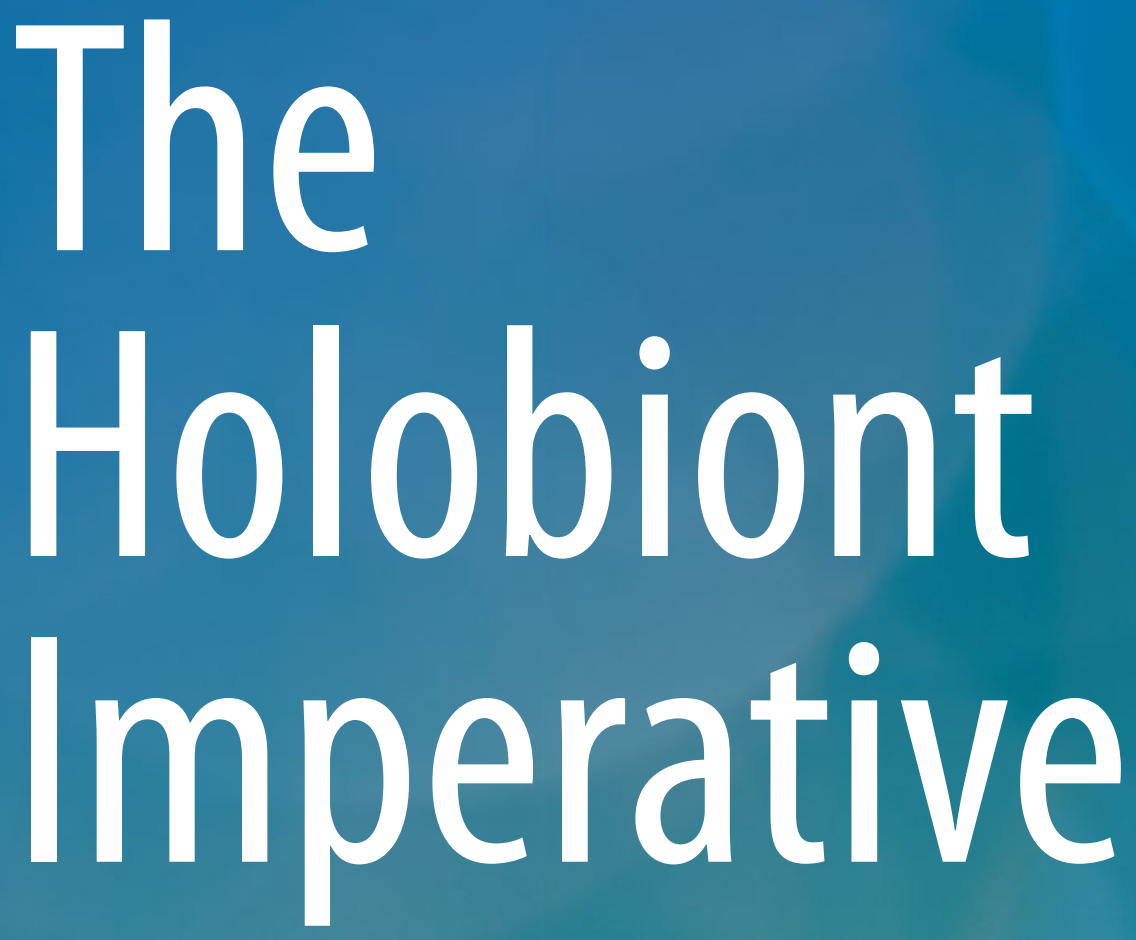

Perspectives from Early Emerging Animals

Springer 
The Holobiont Imperative 

Thomas C. G. Bosch • David J. Miller

\section{The Holobiont Imperative} Perspectives from Early Emerging Animals

Springer

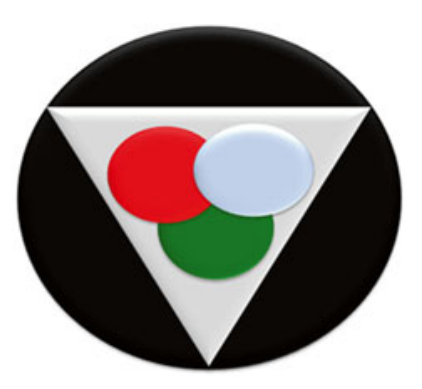


Thomas C. G. Bosch

Zoological Institute

Christian Albrechts Universität zu Kiel

Kiel

Germany
David J. Miller

ARC Cnt. of Execl. for Coral Reef Stud. James Cook University

Townsville, Queensland

Australia

ISBN 978-3-7091-1894-8

ISBN 978-3-7091-1896-2 (eBook)

DOI 10.1007/978-3-7091-1896-2

Library of Congress Control Number: 2016931994

Springer Wien Heidelberg New York Dordrecht London

(C) Springer-Verlag Wien 2016

This work is subject to copyright. All rights are reserved by the Publisher, whether the whole or part of the material is concerned, specifically the rights of translation, reprinting, reuse of illustrations, recitation, broadcasting, reproduction on microfilms or in any other physical way, and transmission or information storage and retrieval, electronic adaptation, computer software, or by similar or dissimilar methodology now known or hereafter developed.

The use of general descriptive names, registered names, trademarks, service marks, etc. in this publication does not imply, even in the absence of a specific statement, that such names are exempt from the relevant protective laws and regulations and therefore free for general use.

The publisher, the authors and the editors are safe to assume that the advice and information in this book are believed to be true and accurate at the date of publication. Neither the publisher nor the authors or the editors give a warranty, express or implied, with respect to the material contained herein or for any errors or omissions that may have been made.

Printed on acid-free paper

Springer-Verlag GmbH Wien is part of Springer Science+Business Media (www.springer.com) 


\section{Acknowledgments}

No matter how many authors are on the cover, every book is the work of many hands. We would like to thank the many people who made this project possible, starting with the contributions of many students, postdocs, and co-investigators over the years. TB thanks particularly to René Augustin and Sebastian Fraune, who initiated work on innate immunity and host-microbe interactions in Hydra. The work related to this review was supported in part by grants from the Deutsche Forschungsgemeinschaft (DFG) and the Clusters of Excellence "The Future Ocean" and "Inflammation at Interfaces" (to TB). DJM gratefully acknowledges the support of the Australian Research Council, both directly and via the ARC Centre of Excellence in Coral Reef Studies, and the unlimited patience of Eldon Ball, a real scholar and remarkable human being. 



\section{Contents}

1 Introduction: The Holobiont Imperative .................. 1

1.1 Of Complex Diseases and Animals as Complex Systems:

Why Bacteria Matter $\ldots \ldots \ldots \ldots \ldots \ldots \ldots \ldots \ldots \ldots \ldots \ldots \ldots \ldots \ldots$

1.2 The Complexity of Coevolved Animal Communities

Was Discovered in 1877 in Kiel, Germany ............... 6

1.3 Looking for a Term for the Functional Entity Formed

by a Host and Its Associated Microbial Symbionts............ 8

References................................ 9

2 Major Events in the Evolution of Planet Earth:

Some Origin Stories $\ldots \ldots \ldots \ldots \ldots \ldots \ldots \ldots \ldots \ldots \ldots \ldots \ldots \ldots \ldots \ldots$

2.1 Microbes Were First: Bacteria Have Existed

from Very Early in the History of Life on Earth ........... 11

2.2 Life Did Not Take Over the Globe by Combat,

But by Networking. . . . . . . . . . . . . . . . 11

2.3 The Transformation of the Biosphere at the Ediacaran-Cambrian Boundary ................ 13

2.4 Our Bacterial Ancestry Is Reflected in Our Genomic Signature . . . . . . . . . . . . . . . . 15

2.5 Genomes of Early Emerging Metazoans, Similar to Humans, Contain a Considerable Fraction

of Genes Encoding Proteins of Bacterial Origin ........... 16

2.6 The CRISPR/CAS System as Window into Ancient Holobionts. . . . . . . . . . . . . . . . . . . . . . 19

2.7 Origins of Complexity: What Makes an Animal? ............ 20

2.8 Multicellularity Requires Cooperation of Cells............ 21

2.9 Genomes of Early Emerging Metazoans Reveal the Origin of Animal-Specific Genes. . . . . . . . . . . . . . . 22

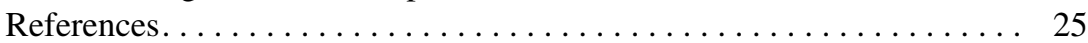

3 The Diversity of Animal Life: Introduction

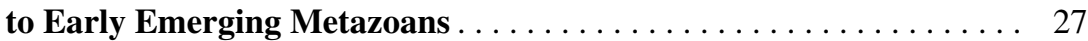

3.1 How Old Are the "Early Diverging" Animal Phyla?.......... 28

3.2 Cnidarians: The Closest Relatives of "Higher"

Animals (Bilateria) . . . . . . . . . . . . . . . . . . 32 


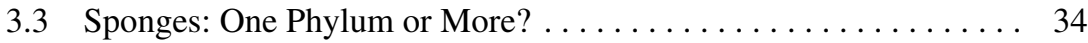

3.4 The "Comb Jellies": The Enigmatic Phylum Ctenophora . . . . . . . . . 39

3.5 Placozoans: The Simplest Extant Animals? . . . . . . . . . . . . 40

3.6 Eyes, Nervous Systems, and Muscles . . . . . . . . . . . . . . 42

3.7 The Closest Unicellular Relatives of Extant Animals . . . . . . . . . . 43

3.8 The Paucity of Data on Symbioses Involving "Lower" Animals . . . 44

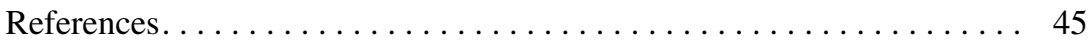

\section{Phylosymbiosis: Novel Genomic Approaches Discover}

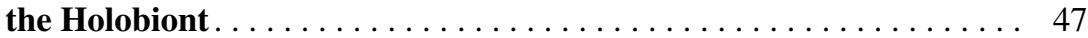

4.1 Animal Life and Fitness Is Fundamental Multiorganismal . . . . . . . 47

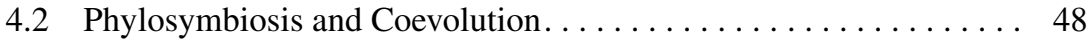

4.3 Microbiota Diversification Within a Phylogenetic Framework of Hosts: Insights from $\mathrm{Hydra} \ldots \ldots \ldots \ldots \ldots \ldots \ldots$

References.......................... 54

5 Negotiations Between Early Evolving Animals

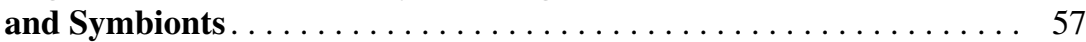

5.1 Cnidaria Use a Variety of Molecular Pathways to Elicit Complex Immune Responses . . . . . . . . . . . . . . . . . . . 57

5.2 How Do Cnidarians Distinguish Between Friends

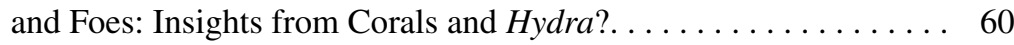

5.3 Selection Can Favor the Establishment of Mutualisms

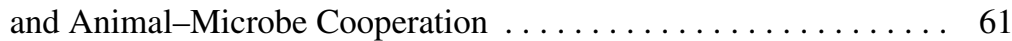

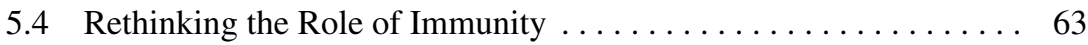

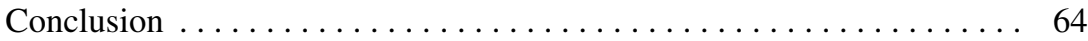

References................................ 65

6 Role of Symbionts in Evolutionary Processes. . . . . . . . . . . . 67

6.1 Microbes as the Forgotten Organ . . . . . . . . . . . . . . 67

6.2 Developmental Symbiosis . . . . . . . . . . . . . . . . . 68

6.3 The Role of Symbionts in Evolutionary Processes . . . . . . . . . . 69

6.4 Nematostella, an Early Metazoan Model to Understand Consequences of Host-Microbe Interactions for Rapid Adaptation of a Holobiont to Changing Environmental Conditions . . . . . . . . . . . . . 71

6.5 Rapid Adaptation to Changing Environmental Conditions: The Coral Probiotic Hypothesis. . . . . . . . . . . . . . 73

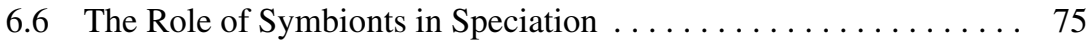

References................................ 76

7 The Hydra Holobiont: A Tale of Several Symbiotic Lineages . . . . . . . . 79

7.1 Rationale for Studying Host-Microbe Interactions

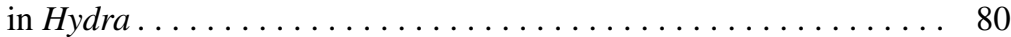

7.2 The Hydra Microbiota . . . . . . . . . . . . . . . 82

7.3 Linking Tissue Homeostasis, Development, and the Microbiota . . . . . . . . . . . . . . . . . . . . . . . 84 
7.4 Hydra's Mucus Layer Plays a Key Role in Maintaining the Necessary Spatial Host-Microbial Segregation. . . . . . . . . . . 86

7.5 Microbes Differ in Embryos and Adult: Embryo Protection. . . . . . . 87

7.6 Antimicrobial Peptides Function as Host-Derived Regulators of Microbial Colonization . . . . . . . . . . . . . 91

7.7 Symbiotic Interactions Between Hydra and the Unicellular Algae Chlorella . . . . . . . . . . . . 93

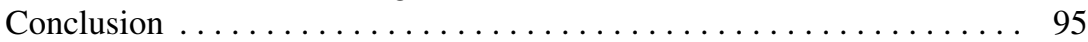

References................................ 96

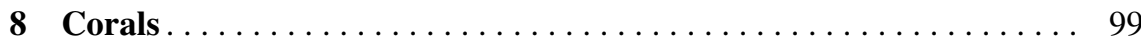

8.1 The Case of Reef Building Corals: A Complex Association Between Animal, Algal, and Bacterial Components .

8.2 Attempts to Generalize About Coral-Microbe Interactions

Are Complicated by the Evolutionary and Physiological

Diversity of Corals . . . . . . . . . . . . . . . . . . . . . . 100

8.3 The Complexity of Coral Microbial Communities . . . . . . . . . 101

8.4 Where Are the Bacteria Located? . . . . . . . . . . . . . . . . . . 102

8.5 Transmission Mode and Ontogeny . . . . . . . . . . . . . . . 103

8.6 Key Components of the Coral Microbiome. . . . . . . . . . . . . 104

8.7 Nitrogen-Fixing Bacteria Are Intimately Associated with Corals . . . . . . . . . . . . . . . . . . . . . . . . . . . . . . . . . . . . 107

8.8 Probiotic Microbes and Antimicrobial Peptides . . . . . . . . . 107

8.9 Coral-Bacterial Interactions Modulate Local Climate

Via Sulfur Metabolites . . . . . . . . . . . . . . . . . . . . . . . . 108

Conclusion ............................. 109

References............................ 110

9 Bleaching as an Obvious Dysbiosis in Corals . . . . . . . . . . . . . 113

9.1 The Complex Relationship Between Stress Sensitivity and the Transmission Mode and Diversity of Symbionts . . . . . 115

9.2 Do Bacteria Cause Coral Bleaching?. . . . . . . . . . . . 116

9.3 Coral Disease and the Significance of Opportunistic Pathogens......................... 116

9.4 Changes in Coral-Associated Microbial Consortia Under Stress . . . . . . . . . . . . . . . . . . . . . . . . . . . . . . . . . . 117

9.5 Symbiodinium as a Recent Intruder on Preexisting Coral-Bacterial Mutualisms ... . . . . . . . . . . . . . . 118

9.6 Coda: Are Coral Reefs Doomed? . . . . . . . . . . . . . . . . . . . 119

9.6.1 The Geological Perspective: The Persistence

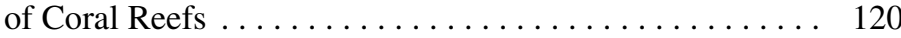

9.6.2 Impacts of Ocean Acidification on Corals . . . . . . . . . . . 122

9.6.3 What About the Direct Impact of Thermal Stress or Elevated $\mathrm{CO}_{2}$ on Corals? 
9.6.4 Can Corals Evolve Fast Enough to Keep Pace with the Rate of Climate Change? . . . . . . . . . . 123

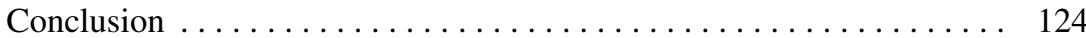

References............................. 124

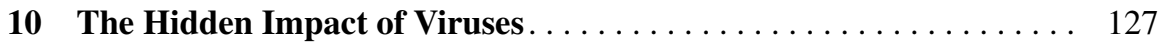

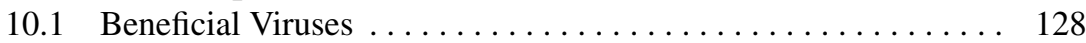

10.2 Viral Communities in Hydra Are Species Specific and Sensitive to Stress . . . . . . . . . . . . . . . . . . . 129

10.3 Bacteriophage Therapy in Corals?................ 131

Conclusion ............................ 132

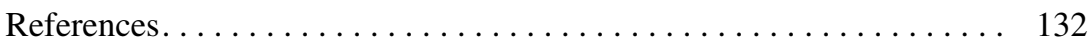

11 Seeking a Holistic View of Early Emerging Metazoans:

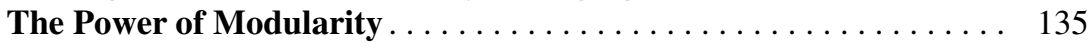

11.1 Animals Are Mobile Ecosystems Carrying a Myriad of Microbes with Them . . . . . . . . . . . . . . . . . 135

11.2 The Power of Modularity. . . . . . . . . . . . . . . . 137

References........................... 138

Further Reading . . . . . . . . . . . . . . . . . . . . . . . . . . . . . . . 139

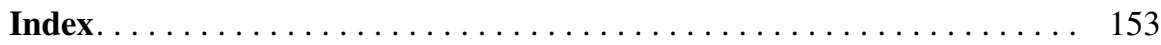

